\title{
The Application of Virtual Reality Technology in Ancient Garden Restoration
}

\author{
Jiwei $\mathrm{Li}^{\mathrm{a}^{*}}$ and Yingchun Cao ${ }^{\mathrm{b}}$ \\ College of Civil Engineering and Architecture, Hebei University, Baoding 071002, China \\ ahbdxljw@126.com, bzjkljw@126.com,
}

Keywords: Virtual reality; Ancient; Garden; Restoration; Reappearance

\begin{abstract}
Most traditional methods of ancient garden restoration are to record with text, charts and graphic drawings and then observe the restoration effect through miniatures or color effect pictures. However, those methods are too inflexible, which cannot reflect the unique artistic conception and steric space of ancient gardens. As an important technology in the computer information age, virtual reality technology is featured with immersion, interaction and imagination. While gardens pay much attention to the experience and feeling of people, which places a high application value on the virtual reality technology in the restoration and scene reconstruction of ancient gardens. Through the analysis of methods and means of virtual reality technology in the restoration of ancient gardens and based on the restoration design of Ancient Lotus Pond Garden, this paper has studied the detailed application methods of virtual reality technology in the restoration of ancient gardens and completed the restoration design of Ancient Lotus Pond Garden. The study shows that human-computer interaction technique allows modern people to experience virtual wandering and scene reappearance in ancient gardens and feel the unique spatial artistic conception of ancient gardens.
\end{abstract}

\section{Introduction}

Numerous ancient architectures and gardens carry the history, culture and soul of China, without which we will lose our cultural deposits and developing direction [1]. Therefore, it is necessary for us to protect, repair and restore the ancient architectures and gardens.

Most traditional methods of ancient garden restoration are to record with text, charts and graphic drawings and then observe the restoration effect through miniatures or color effect pictures [2]. However, those methods are too inflexible, which cannot reflect the unique artistic conception and steric space of ancient gardens [3]. While virtual reality provides a new way of expression for the restoration design of ancient gardens. It can use the computer to simulate the three-dimensional space of the real world and the natural environment, which allows people to feel the three-dimensional space created by computer through visual, hearing, and touch senses, and thus generate an immersive interactive scene simulation effect [4].

\section{Virtual Reality Technology}

Virtual reality technology can make people have strong feelings to the computer data through computer processing, which is mainly due to several technical features widely known as "3I" features: Immersion, Interaction and Imagination [5]. This feeling and experience is exactly what we need in the restoration of ancient gardens. To apply the virtual reality technology in the field of ancient gardens for the restoration of architecture environment and virtual wandering will help us to deliberate and explore the space scene and courtyard space and strongly promote the development of restoration techniques of ancient gardens.

The virtual reality technology allows users to feel the ancient garden space represented by data, stimulate with multiple motion manners and observe garden works in certain angles [6]. Particularly, it allows people to roam in gardens in the first perspective and observe any places that can be seen in the scene in vivid roaming manners such as walking, jogging and fighting according to the head movement 
features and imaging features of human eyes [7]. This way of representation is more free and real than the three-dimensional animation [8].

\section{Application Advantages of Virtual Reality Technology in Ancient Garden Restoration}

China has created brilliant culture and numerous outstanding gardens in the time variation in its long history. However, due to wars and historical reasons, only a few of them remain relatively complete without too much damage. A large number of ancient gardens were damaged and only left some sites. These remained and destroyed gardens are all precious cultural heritage. How to protect and restore those cultural heritages has been a difficult problem for antiquarian antiquary. In the restoration process of ancient gardens, how to grasp the original space to better represent the original artistic conception of gardens is a key research direction for the restoration of ancient gardens. The emergence and development of virtual reality technology provides new thoughts and methods for the restoration of the lost gardens, which can achieve the recording and protection of ancient gardens more convenient and vividly. Virtual reality technology will be an important application direction for the reappearance of ancient gardens with digital data on computer.

Because ancient gardens pay much attention to personal feelings, the garden space layout, construction monomer, overall artistic conception and other elements will be carefully designed. Therefore, to successfully restore ancient gardens, immersive feel will be an essential element, which fit well with the "immersion" or "interaction" of virtual reality technology [9]. The "interaction" of virtual reality allow people to roam in gardens and experience the winding path leading to a secluded spot and other unique spatial feelings, thus achieving the restoration and representation of the architecture environment and garden conception of ancient gardens. And all of these can be realized by virtual reality technology, which allows the researchers and users to visit, walking and experience the artistic conception of garden architectural space whenever and wherever possible.

\section{Restoration Design of Ancient Gardens with Virtual Reality Technology}

In order to restore ancient gardens with virtual reality technology and achieve ideal space artistic conception, raw data of gardens needs to be collected to analyze the spatial, cultural and architectural features. After obtaining the information, control the main space effect and conduct digital restoration with computer. The restoration process is divided into the following steps:

Data Information Collection and Preparation. The date information collection and preparation is mainly to determine the restoration period of the object to be designed, collect relevant information with field investigation, literature review and other technical means to gather the detailed information of buildings, sites and plants to convert whole space scene into clear and complete data.

Data Information Entry. Enter the data information collected in the previous stage into computer to form the information that can be identified by the computer, and then convert the buildings, sites and plants into 3D computer model with computer software so that the virtual garden space can be seen with a computer.

Data Information Integration. Based on the 3D information model and the garden space processing technique, analyze research and debug and arrange each scene, and finally complete the virtual 3D scene representation of the whole garden space. Input the completed scene information to the virtual reality software for integration, adjustment and modification to achieve the reappearance effect of ancient gardens.

Information Interaction Feedback. Input the completed information model to the interaction system, realize the human-computer interaction and information feedback through the outside information input and operation and finally realize ideal simulation effect, represent the perfect effect of ancient gardens and complete the virtual restoration of ancient gardens. 


\section{Virtual Reality Case Application of Ancient Gardens}

This case application selects the Ancient Lotus Pond Garden in Baoding City as the virtual reality restoration object to verify the previous research results. The Ancient Lotus Pond Garden has vital historic significance in historical development of gardens in Baoding even China and great value of cultural studies.

Introduction to the Ancient Lotus Pond Garden. Baoding Ancient Lotus Pond Garden has a long history and culture, which has experienced many renovations as a result of social development and changes: from private garden to temporary imperial palace of Emperor Qianlong, Jiaqing and Guangxu as well as Empress Dowager Cixi, then turned into a college garden and finally became a park. In the eight hundred years of history changes, it has experienced booms and busts as well as joy and sorrow. Meanwhile, it has indirectly reflected the historical development and changes of Hebei Province even China since the end of Jin Dynasty. Therefore, this paper hopes to display the original appearance of the Ancient Lotus Pond Garden and the historical culture by the restoration design of the Ancient Lotus Pond Garden and thus realize the protection and display.

The Ancient Lotus Pond Garden has fully displayed the historical value and cultural value of the heritage with its unique garden spatial feature. With orderly layout and well-arranged landscape, the garden is elegant and unique, which has long been known "Urban Penglai" and "Small West Lake"[10].At present, Shuidong Tower, Zaoyong Tower, Junzichangsheng Pavilion, Xiangqin Pavilion, Gaofen Pavilion, Hanlv Pavilion, Wanhong Pavilion, Guanlan Pavilion and other buildings remain in the garden. The beautiful Wanhong Bridge, Jiuqu Bridge and ancient Lvyeti Bridge between the rockery, rare stones, woods and ponds form a beautiful scroll painting with "landscape in lake and poem in landscape".

Although the scenery is still beautiful, it is not the original picture after many times of destruction and damage in the history. Located in the downtown district and surrounded by commercial buildings, it has completely lost the artistic conception at that time. Besides, due to the change and destruction of the sites and buildings, the artistic conception of ancient garden has disappeared, and the famous "Twelve Landscapes in Lotus Pond" has become incomplete. Therefore, it is necessary to represent its glory days and important cultural connotation.

Process of Restoration and Virtual Reality. Step One: investigate the environment of Ancient Lotus Pond Garden and the neighborhood block, take pictures and conduct field survey and investigation to the Lotus Pond, measure the existing ancient buildings and landscapes, analyze the hypsography changes, and refer the relevant historical data and the collection of literature. Through these analysis and comparison, determine the period of Emperor Guangxu as restoration time point (Fig. 1), and prepare the detailed data of the situation in the park. Consult building deformation, scale, location, plan and other specific information of the Lotus Pond at that time, and make overall layout space analysis on the of topography, river banks, buildings, landscape sketch, rocks, and plants of the Ancient Lotus Pond Garden in the restoration period. 


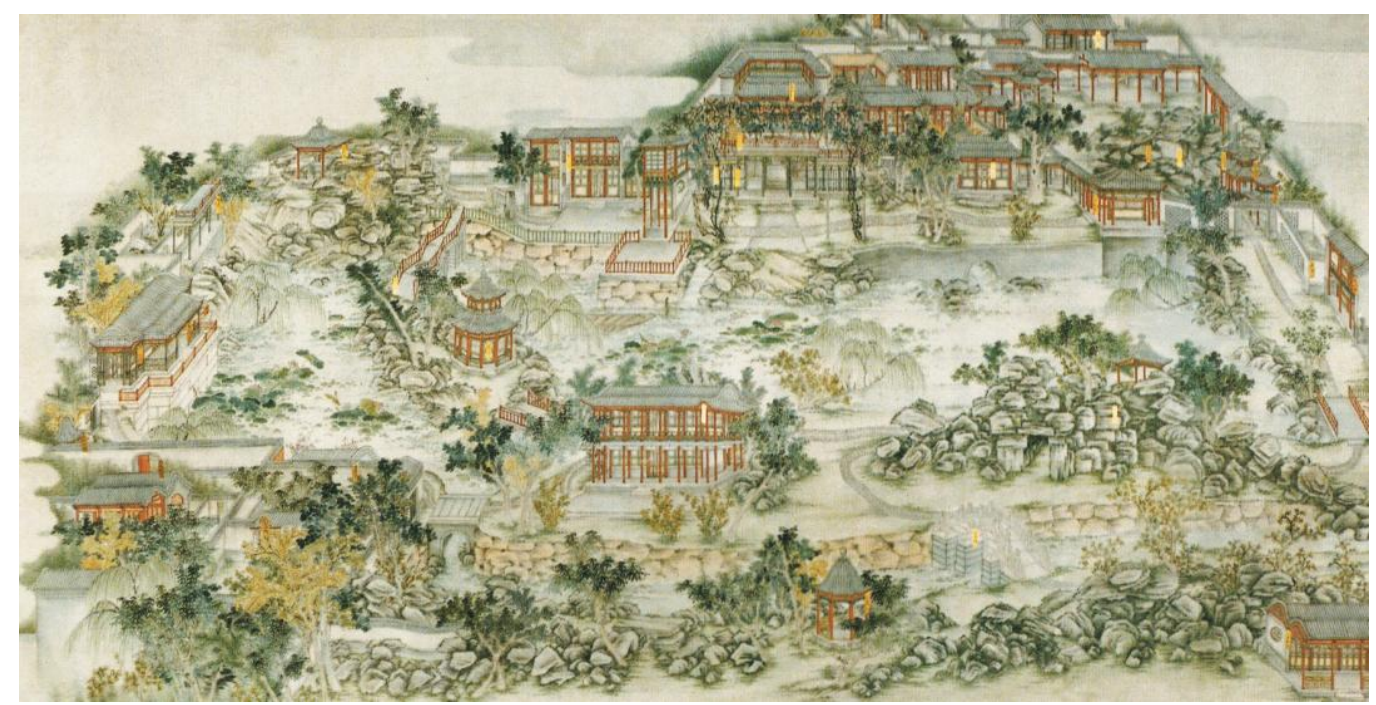

Figure 1. Ancient Lotus Pond Garden in Period of Emperor Guangxu

Step Two: input the data information and build the geometric model Use computer aided design software for data arrangement of planar distribution, draw the architecture environment information of various locations on electronic drawings. Then, use the three-dimensional modeling software to produce the models of architecture, topography, river bank, pond, and plants, and restore the collected real texture on the models. One important job here is model simplification and texture processing: reduce the planes of models without affecting the visual effect to reduce the calculation of computer, improve the data processing rate and enhance the restoration degree of images.

Step Three: after the baking processing in the three-dimensional modeling software, input the three-dimensional space model to virtual roaming processing software for spatial analysis and debugging, and create the expected spirit artistic conception and spatial features of the Ancient Lotus Pond Garden by creating and restoring the scene with Chinese classical garden imagery.

Finally, comprehensively adjust to realize the virtual roaming of Ancient Lotus Pond Garden. By inputting external information, computer will generate feedback. Through debugging and testing, finally achieve the building restoration and virtual roaming display of the Ancient Lotus Pond Garden, as shown in Fig. 2. In the virtual scene, one can experience the interaction by free roaming and pre-determined route roaming at every corner of the whole Ancient Lotus Pond Garden and enjoy the landscape in Ancient Lotus Pond Garden during the period of Emperor Guangxu. 


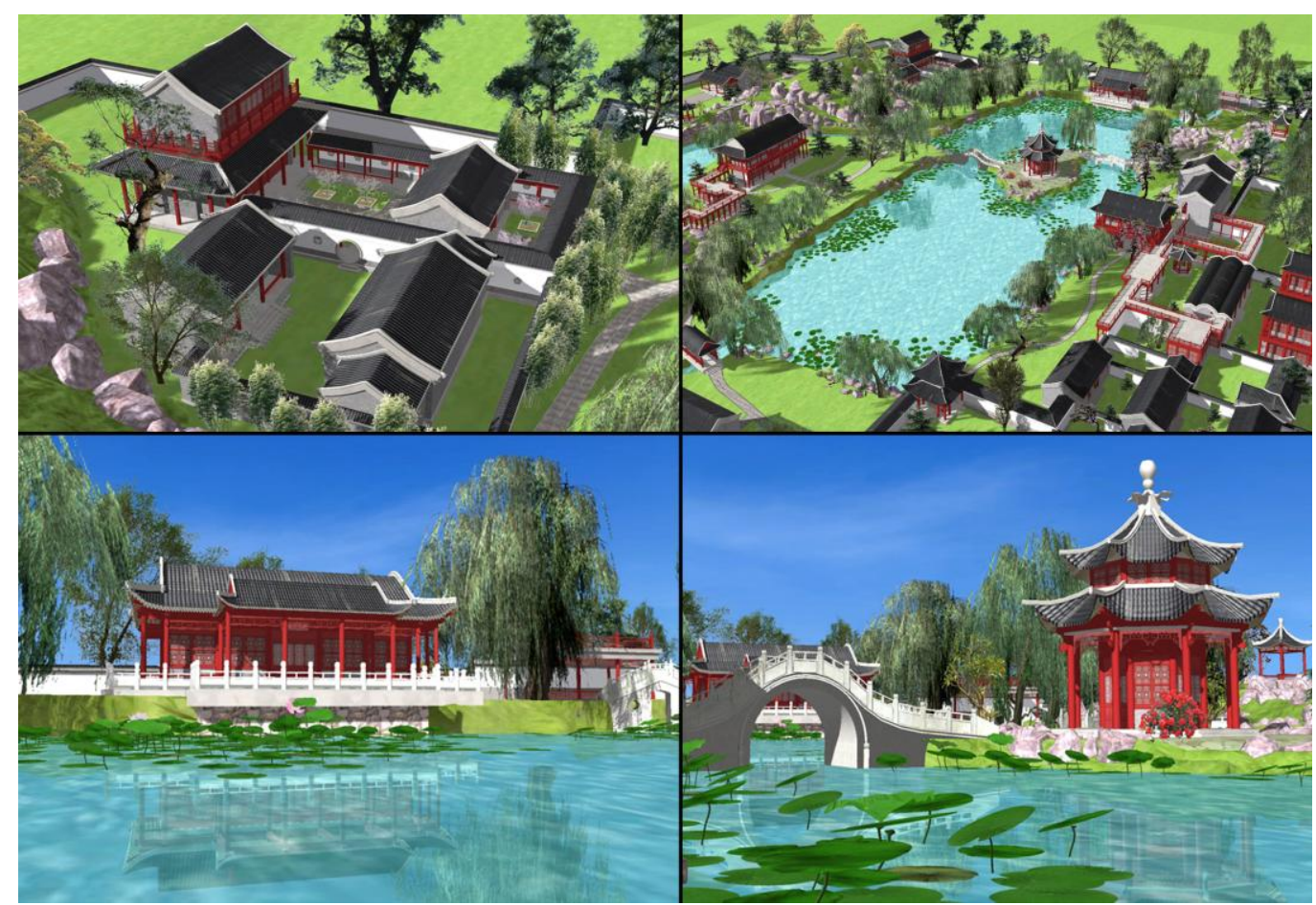

Figure 2. Restoration and virtual roaming display of Ancient Lotus Pond Garden

Through virtual restoration design of Ancient Lotus Pond Garden, the virtual roaming system is established, which allow people to visit the Ancient Lotus Pond Garden in the digital model and experience the space artistic conception of ancient gardens. More people can learn about the culture of Ancient Lotus Pond Garden with virtual roaming, and get involved in the protection. Most of all, the Ancient Lotus Pond Garden can long survive in the digital world.

\section{Application Significance of Virtual Reality Technology in Ancient Garden Restoration}

Ancient Lotus Pond Garden restored this time is just one of the numerous ancient gardens in China, which are to be protected and repaired. People living in the modern society need such restoration and need to experience the lost ancient gardens, activate our culture and understand our history.

The disappeared classical gardens represent the historical image of a city and carry the vicissitudes of a city. The development and changes of those gardens can reflect the development level of the culture, science and technology at that time, which allow people to learn about the long history of cities. The restoration design can make a city forever refresh its charm and glory. These historical and cultural heritages have very high historical, artistic value and scientific research value, and can reflect the changes, vicissitude and evolution as well as the evolution of human culture. The repair and restoration design of ancient gardens with virtual reality technology can vividly represent the cultural products and display the cultural deposits of Chinese Nation. If we can't make the fullest use of these new technologies for restoration design of the classical gardens, the human culture will disappear when they are completely destroyed and lost. The most advanced technology should be adopted for the repair and restoration design of the existing classical gardens and to conduct digital protection so as to continue the human civilization.

\section{References}

[1] Y.G. Peng: Analysis of Chinese Classical Gardens (China Architecture \& Building Press, China 1986), p.26. (In Chinese)

[2] C. Biagini, P. Capone, V. Donato and N. Facchini: Automation in Construction, Vol.71 (2016), p.74-86. 
[3] Q.W. Hu, S.H. Wang, C.W. Fu, M.Y. Ai, D.B. Yu and W.D. Wang: Remote Sensing, Vol.8 (2016) No.4, p.1-10.

[4] S. Chen, Q. Hu, S. Wang and H. Yang: Remote Sensing, Vol.8 (2016) No.10, p.1-18.

[5] S. Li, M. Hou, Y. Wu, Y. Hu and Y. Zhang: Urban Geotechnical Investigation and Surveying, (2013) No.2, p.85-88. (In Chinese)

[6] E. Madrigal, S. Prajapat and J.C. Hernandez-Prera: American Journal of Clinical Pathology, Vol.164 (2016) No.4, p.462-468.

[7] C.M. Lai: Interactive Learning Environments, Vol.24 (2016) No.1, p.1-17.

[8] J. Cao, X. Xing and X. Zeng: Information Technology Journal, Vol.12 (2013) No.14, p.2913-2917.

[9] S.P. Chan, Q.T. Le, A. Pedro and C.R. Lim: Journal of Professional Issues in Engineering Education and Practice, Vol.164 (2016) No.4, p.462-468.

[10]F.F. Meng: Ancient Lotus Pond Garden (Hebei People's Publishing House, China 1984), p.120. (In Chinese) 